\title{
The Predialysis Serum Sodium Level Modifies the Effect of Hemodialysis Frequency on Left- Ventricular Mass: The Frequent Hemodialysis Network Trials
}

\author{
Jochen G. Raimann ${ }^{a}$ Christopher T. Chan ${ }^{b}$ John T. Daugirdas ${ }^{c}$ \\ Thomas Depner $^{d}$ Tom Greene ${ }^{e}$ George A. Kaysen ${ }^{d}$ Alan S. Kliger ${ }^{f}$ \\ Peter Kotanko $^{\text {a,g }} \quad$ Brett Larive $^{\mathrm{h}} \quad$ Gerald Beck $^{\mathrm{h}}$ Robert McGregor Lindsay ${ }^{\mathrm{i}}$ \\ Michael V. Rocco ${ }^{j}$ Glenn M. Chertow ${ }^{k}$ Nathan W. Levin ${ }^{\mathrm{a} g}$ the Frequent \\ Hemodialysis Network (FHN) Trial Group

\begin{abstract}
aRenal Research Institute, New York, NY, USA; bUniversity Health Network Toronto, Toronto, ON, Canada; ' University of Illinois College of Medicine, Chicago, IL, USA; dUniversity of California Davis, Davis, CA, USA; eUniversity of Utah,

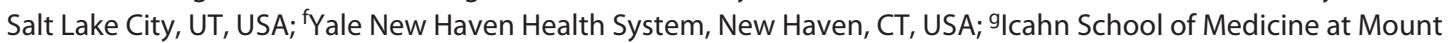
Sinai Health System, New York, NY, USA; ${ }^{h}$ Cleveland Clinic Foundation, Cleveland, OH, USA; 'Western University, London, ON, Canada; 'Wake Forest School of Medicine, Winston-Salem, NC, USA; ${ }^{2}$ Stanford University School of Medicine, Stanford, CA, USA
\end{abstract}

\section{Keywords}

Frequent hemodialysis · Left-ventricular mass · Blood pressure $\cdot$ Fluid overload $\cdot$ Effect modification

\begin{abstract}
Introduction: The Frequent Hemodialysis Network (FHN) Daily and Nocturnal trials aimed to compare the effects of hemodialysis (HD) given 6 versus 3 times per week. More frequent in-center HD significantly reduced left-ventricular mass (LVM), with more pronounced effects in patients with low urine volumes. In this study, we aimed to explore another potential effect modifier: the predialysis serum sodium (SNa) and related proxies of plasma tonicity. Methods: Using data from the FHN Daily and Nocturnal Trials, we compared the effects of frequent HD on LVM among patients stratified by $\mathrm{SNa}$, dialysate-to-predialysis serum-sodium gradient $(\mathrm{GNa})$, systolic and diastolic blood pressure, time-integrated
\end{abstract}

karger@karger.com www.karger.com/kbr

Karger $\stackrel{\text { ' }}{5}$

GOPEN ACCESS
(C) 2021 The Author(s)

Published by S. Karger AG, Basel

This is an Open Access article licensed under the Creative Commons Attribution-NonCommercial-4.0 International License (CC BY-NC) (http://www.karger.com/Services/OpenAccessLicense), applicable to the online version of the article only. Usage and distribution for commercial purposes requires written permission. sodium-adjusted fluid load (TIFL), and extracellular fluid volume estimated by bioelectrical impedance analysis. Results: In 197 enrolled subjects in the FHN Daily Trial, the treatment effect of frequent $\mathrm{HD}$ on $\triangle \mathrm{LVM}$ was modified by $\mathrm{SNa}$. When the FHN Daily Trial participants are divided into lower and higher predialysis SNa groups (less and greater than 138 $\mathrm{mEq} / \mathrm{L}$ ), the LVM reduction in the lower group was substantially higher $(-28.0[95 \% \mathrm{Cl}-40.5$ to -15.4$] \mathrm{g})$ than in the higher predialysis SNa group $(-2.0[95 \% \mathrm{Cl}-15.5$ to 11.5$] \mathrm{g})$. Accounting for $\mathrm{GNa}$, TIFL also showed more pronounced effects among patients with higher GNa or higher TIFL. Results in the Nocturnal Trial were similar in direction and magnitude but did not reach statistical significance. Discussion/ Conclusion: In the FHN Daily Trial, the favorable effects of frequent HD on left-ventricular hypertrophy were more pronounced among patients with lower predialysis $\mathrm{SNa}$ and higher GNa and TIFL. Whether these metrics can be used to identify patients most likely to benefit from frequent $\mathrm{HD}$ or 
other dialytic or nondialytic interventions remains to be determined. Prospective, adequately powered studies studying the effect of GNa reduction on mortality and hospitalization are needed.

(c) 2021 The Author(s)

Published by S. Karger AG, Basel

\section{Introduction}

Cardiovascular risk is markedly increased in patients with reduced glomerular filtration rate [1], and the risk of adverse cardiovascular outcomes does not improve following commencement of standard renal replacement therapy [2]. Adverse cardiovascular outcomes result from increased vascular events, often in association with inflammation $[1,3]$ and an increased incidence of congestive heart failure and left ventricular hypertrophy $(\mathrm{LVH})$ [4]. The prevalence and severity of $\mathrm{LVH}$ are increased in patients with decreased residual diuresis [5] and with increased volume load [6-8]. LVH is also associated with higher serum concentrations of fibroblast growth factor-23 which is upregulated in response to hyperphosphatemia $[9,10]$.

Sodium management and control of excessive extracellular fluid volume (ECFV) have proven effective in reducing blood pressure (BP) $[4,11,12]$ and in decreasing the risk of LVH $[4,6,12]$. Beneficial effects on both BP control and LVH have been reported with use of more frequent hemodialysis (HD), a modification of the conventional thrice-weekly dialysis regimen, which, in addition to improving volume control, also facilitates control of hyperphosphatemia and improves health-related quality of life [13].

In 2003, the National Institute of Health and the Centers for Medicare and Medicaid Services (CMS) initiated the Frequent Hemodialysis Network (FHN) Daily and Nocturnal Trials. The trials were designed to establish the safety and efficacy of more frequent HD on 2 co-primary endpoints: death or change in left-ventricular mass (LVM) and death, or change in the Physical Health Composite of the RAND-36 instrument $[14,15]$. The effect of frequent HD on the co-primary and a series of secondary outcomes have been previously reported [12, 16-21].

To quantify the interdialytic volume overload, we computed a novel parameter designed to represent a time-integrated ("area-under the curve") estimate of time-integrated sodium-adjusted fluid load (TIFL), a concept which was reported to associate with changes in LVM in the trials [12]. During the development of the TIFL, which incorporates serum sodium ( $\mathrm{SNa}$ ) and the dialysate to $\mathrm{SNa}$ gradient $(\mathrm{GNa})$, we noticed that the favorable treatment effect (i.e., a reduction in LVM) appeared to be more prominent among patients with lower predialysis $\mathrm{SNa}$ values and those with higher dialysate to $\mathrm{GNa}$ values. The purposes of this study were to quantify this effect and to explore a number of possible mechanisms that might explain the effect modification, especially those related to ECFV and inflammation.

\section{Materials and Methods}

\section{Patient Selection}

Patients for the Daily Trial (ClinicalTrials.gov number: NCT00264758) were recruited by 2 consortia of in-center HD units, one organized by the Renal Research Institute in New York, USA and the other by dialysis units at university and freestanding HD centers in California and Texas. Patients for the separate Nocturnal Trial (ClinicalTrials.gov: NCT00271999) were recruited from home-dialysis training centers in the United States and Canada. All patients signed informed consent. Both trials were approved by local Institutional Review Boards (Beth Israel Medical Center in New York, NY, USA; Stanford University School of Medicine in Stanford, CA, USA and Wake Forest School of Medicine, in Winston-Salem, NC, USA) and conducted according to the Declaration of Helsinki.

\section{Study Design}

The FHN Daily and Nocturnal trials were controlled and randomized. The co-primary endpoints were assessed after a followup period of 12 months [22]. Inclusion and exclusion criteria were nearly identical for both trials, except for residual kidney function at trial entry. In the Daily Trial, we excluded patients with residual urea clearance $>3 \mathrm{~mL} / \mathrm{min}$ per $35 \mathrm{~L}$ of urea distribution volume, while in the Nocturnal Trial, where practical recruitment issues required a focus on incident patients, we set the residual kidney function exclusion considerably higher and accepted patients with average residual clearances of urea and creatinine up to $10 \mathrm{~mL} / \mathrm{min}$ per $1.73 \mathrm{~m}^{2}$ [22].

\section{Measurements}

We performed cardiac magnetic resonance imaging at baseline and at month 12 . SNa was measured monthly by potentiometric methods in certified local laboratories. Dialysate $\mathrm{Na}(\mathrm{DNa})$ was not measured but retrieved from the dialysis provider medical record for each patient at each time point. The sodium gradient during HD (Gna) was calculated as the prescribed DNa minus the measured predialysis $\mathrm{SNa}$. Interdialytic weight gains were assessed according to the dialysis facility routine. To quantify the interdialytic volume overload, we computed a novel parameter designed to represent a time-tntegrated ("area under the curve") estimate of extracellular fluid load (TIFL). The TIFL curve was computed based on the interdialytic weight gain, which is affected by the residual urine volume, the GNa, and the session length. Based on data collected in a previous study, we calculated an estimated postdialysis $\mathrm{SNa}$ as outlined in [12]. This estimated post-dialysis $\mathrm{SNa}$ was in turn used to estimate the volume of post-dialysis fluid intake required after dialysis to restore the predialysis $\mathrm{SNa}$ level to its 


\section{Frequent Hemodialysis Network (FHN) trials}
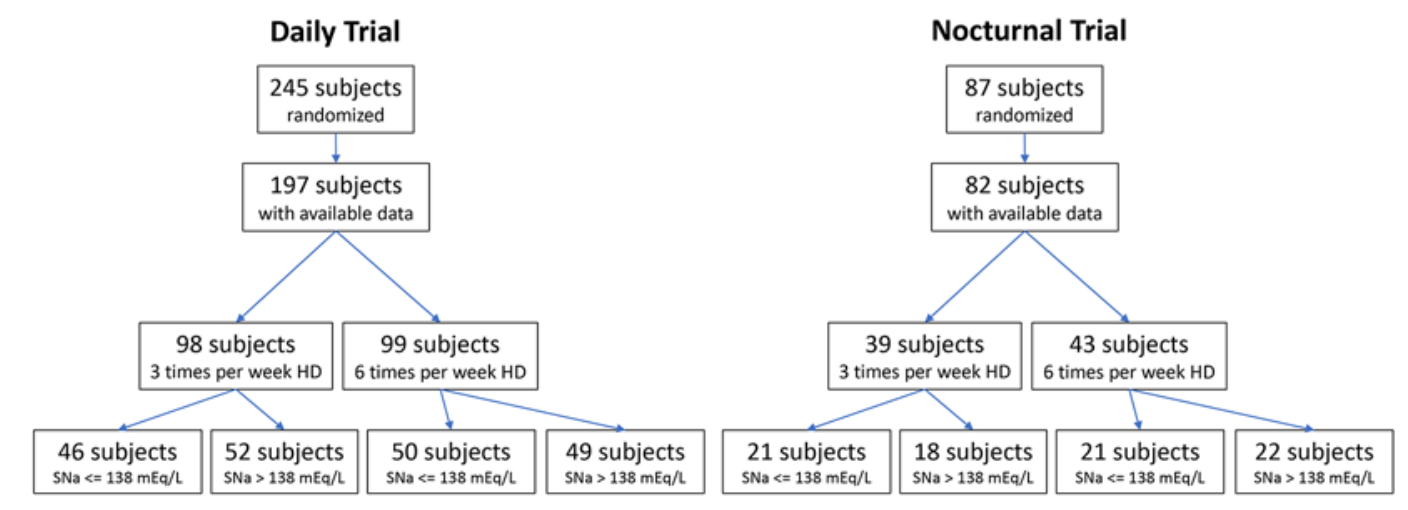

Fig. 1. Flowchart of patient inclusion. FHN, Frequent Hemodialysis Network; HD, hemodialysis.

usual value. This sodium-gradient-adjusted modeled TIFL aims to separately account for both the thirst-driven immediate post-dialytic fluid intake and the sodium and fluid intake during the remainder interdialytic period. The value for TIFL is calculated in liter $\times$ days or the number of liters of extracellular fluid (ECF) overload times the number of days in the interdialytic interval that this overload exists. The value for TIFL is different from conventional time-integrated fluid overload measures in that it also takes into account the gradient between dialysate and predialysis $\mathrm{SNa}$, making the assumptions that the post-dialysis SNa will be very close to the dialysate value, and also that, soon after cessation of dialysis, a patient will drink until the $\mathrm{SNa}$ returns to its predialysis value. In a previous publication, we found that the calculated value for improvement in TIFL in liter $\times$ days with more frequent dialysis was associated with reduction of LVM, unless substantial residual renal function was present [12]. For details on the model see [12] and for simulations of TIFL for subjects with different gradients in the 2 study arms see online supplementary Figure 1; for all online supplementarymaterial,seewww.karger.com/doi/10.1159/000519339.

\section{Bioimpedance Measurements}

We used single frequency bioimpedance analysis (BIA) (RJL Systems, Clinton Township, MI, USA) to estimate body water compartments. As per protocol, we performed BIA prior to a midweek HD treatment; however, deviations in a minority of cases may be noted. Accuracy and precision of the BIA method that was used have been reported elsewhere $[23,24]$. ECFV was calculated as the difference between BIA-estimates of total body water [25] and intracellular fluid volume [26].

\section{Statistical Analyses}

We evaluated the treatment effect of frequent versus conventional HD on LVM by employing linear mixed-effects models adjusted for clinical center, age, diabetes mellitus, and baseline value. We explored effect modification by inclusion of the interaction term between treatment effect and the respective parameter in the linear mixed-effects model and subsequent analysis in strata of that parameter. Changes in LVM were further depicted as a boxwhisker plot stratified into quintiles of $\mathrm{SNa}$. $p$ values $<0.05$ were considered significant. We conducted all analyses using SAS version 9.2 (SAS Institute, Cary, NC, USA) and R v3.6.0 (codename "Planting of a Tree"; [27]) using packages dplyr, reshape2, stringr, doBy, haven, and stringr.

\section{Results}

We included 197 patients enrolled in the FHN Daily trial and 82 patients enrolled in the FHN Nocturnal Trial with available data for $\mathrm{SNa}$ at baseline (Fig. 1). Demographics for the overall population stratified as per the median predialysis $\mathrm{SNa}(138 \mathrm{mEq} / \mathrm{L})$ are shown in $\mathrm{Ta}$ ble 1.

\section{SNa Modifies the Effect of Frequent HD on LVM}

Irrespective of the treatment allocation, $\mathrm{sNa}, \mathrm{dNa}$, and the resulting $\mathrm{GNa}$, remained consistent in magnitude for the studied population over the entire period of the study (online suppl. Fig. 2a-c). In both the Daily and the Nocturnal Trial, $\mathrm{SNa}$ at baseline was not significantly different in patients with congestive heart failure, myocardial infarction, or those with an open prescription of antihypertensive medication at baseline in both trials.

As shown in online supplementary Table 1 and Figure 2 , baseline predialysis sNa significantly modified the effect of frequent HD on LVM ( $p=0.027)$; the interaction of treatment $\times$ baseline $\mathrm{GNa}$ was of marginal significance 


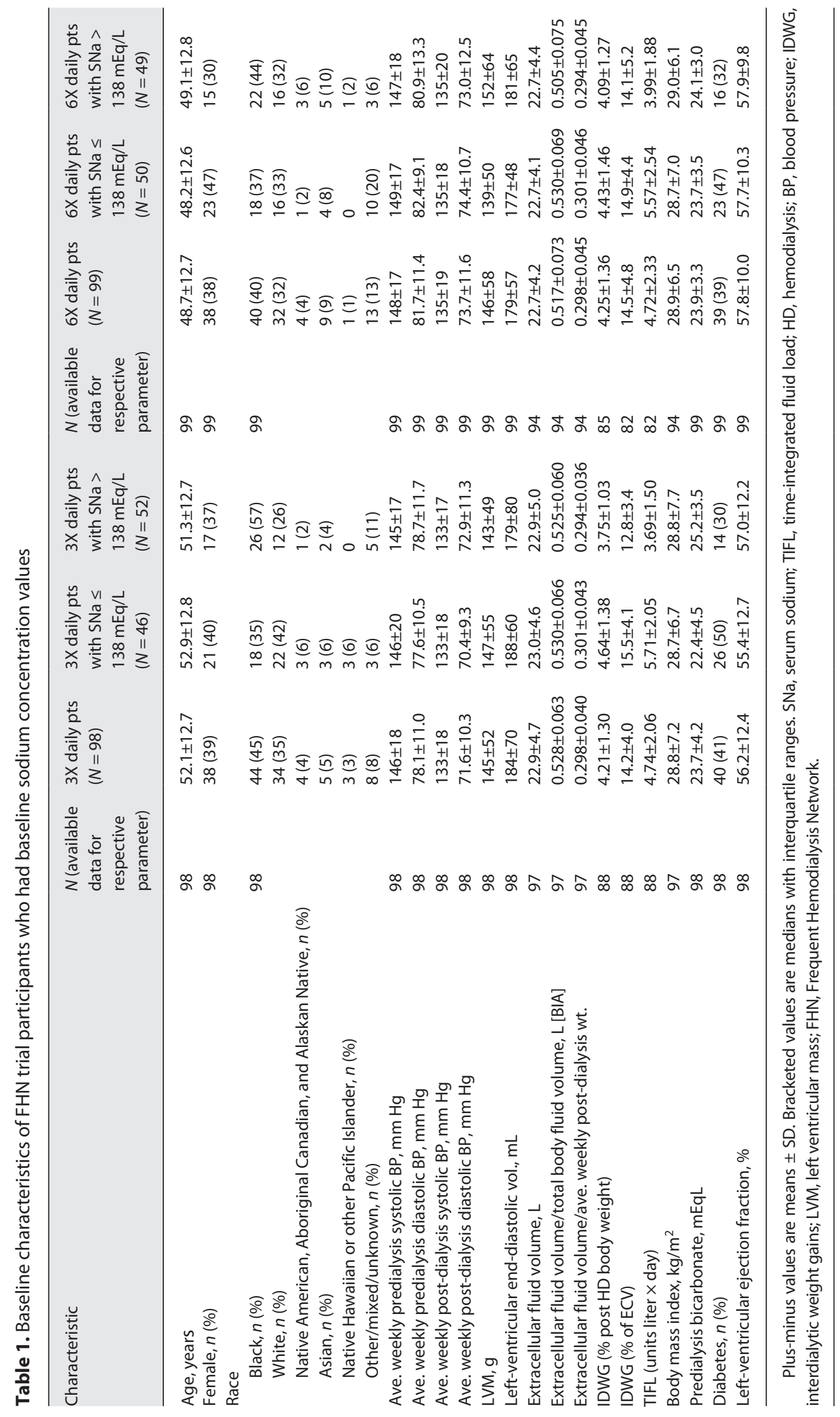




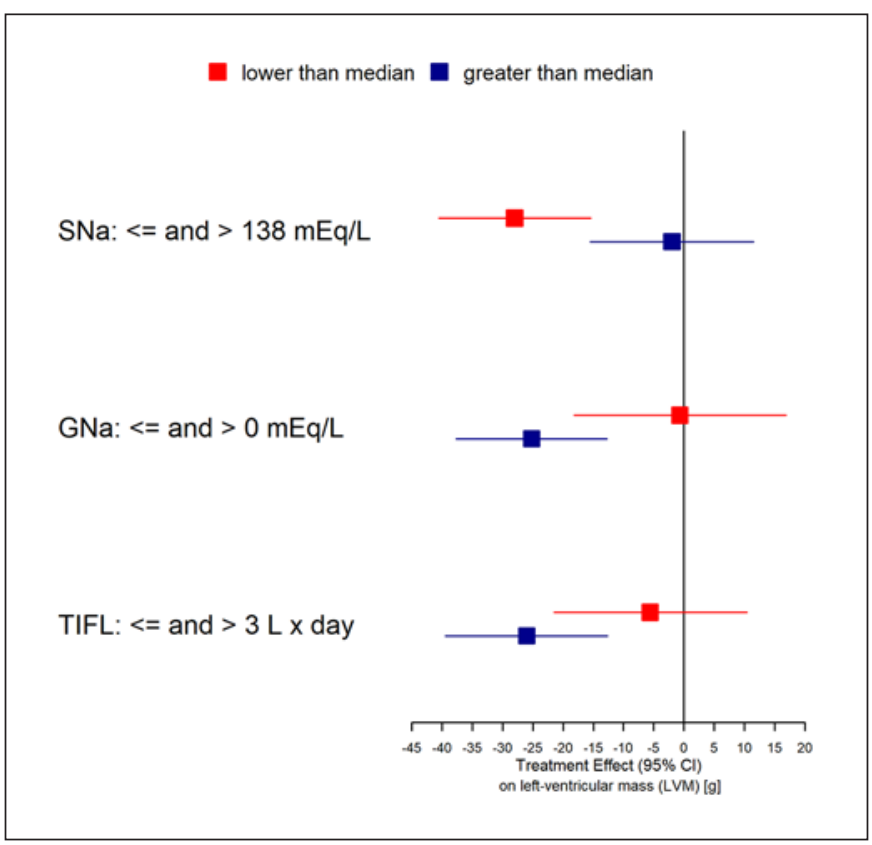

Fig. 2. Forest plot depicting the magnitude of treatment effect of more frequent HD on LVM reduction in subgroups of parameters tested for interaction. LVM, left-ventricular mass; HD, hemodialysis.

$(p=0.06)$. Stratified by median values, the change in LVM was $-28.0(95 \% \mathrm{CI}-40.5$ to -15.4$) \mathrm{g}$ in patients with baseline $\mathrm{sNa} \leq 138 \mathrm{mmol} / \mathrm{L}$ and $-2.0(95 \% \mathrm{CI}-15.5$ to 11.5$) \mathrm{g}$ in patients with baseline $\mathrm{sNa}>138 \mathrm{mmol} / \mathrm{L}$; online supplementary Table 1 . Repeating the analyses stratifying by quintiles of $\mathrm{SNa}$ showed a comparable trend (Fig. 3). For $\mathrm{GNa}$, the interaction of treatment $\times$ baseline GNa was only of borderline significance $(p=0.06)$. Reductions in LVM associate with more frequent $\mathrm{HD}$ for patients with a positive gradient $(\mathrm{GNa}>0 \mathrm{mEq} / \mathrm{L})$ were $-25.2(95 \% \mathrm{CI}$ -37.6 to -12.7$) \mathrm{g}$ and -0.7 (95\% CI -18.2 to 16.8$) \mathrm{g}$; online supplementary Table 1 . In the Nocturnal Trial where the power to detect interactions was considerably lower, the findings regarding $\mathrm{SNa}, \mathrm{GNa}$, and TIFL were of similar direction, but none were statistically significant (online suppl. Tables 2, 3).

\section{TIFL as an Effect Modifier}

Formal testing of the treatment $\times$ TIFL interaction was not significant $(p=0.22)$. However, when stratified by TIFL $\leq 3.0 \mathrm{~L} \times$ days and TIFL $>3 \mathrm{~L} \times$ days, we observed a more pronounced effect in the latter group (-26.0 [95\% CI -39.43 to -12.59 ] g) for those with greater TIFL (online suppl. Table 1 and Fig. 2). In the Nocturnal Trial the treatment effects were smaller and of comparable magnitude in terms of direction and subgroup differences but not statistically significant (online suppl. Table 3 ).

\section{Discussion/Conclusion}

Our analysis quantified and documented our observation that in patients with lower predialysis $\mathrm{SNa}$ values, the use of frequent HD was associated with a more marked reduction in $\mathrm{LVH}$ than those with higher predialysis $\mathrm{SNa}$ values. When the FHN Daily Trial participants are divided into lower and higher predialysis $\mathrm{SNa}$ groups, the LVM reduction in the lower group was substantially higher $(-28.0$ [95\% CI -40.5 to -15.4$] \mathrm{g})$, than in the higher predialysis SNa group $(-2.0$ [ $95 \% \mathrm{CI}-15.5$ to 11.5 ] g); see online supplementary Table 1 and Figure 2. This interaction was statistically significant and remained significant when the predialysis $\mathrm{SNa}$ level was examined as a continuous interaction variable. Notably, assignment to more frequent dialysis had no effect on the predialysis $\mathrm{SNa}$ value.

When examining potential mechanisms for the treatment effect of predialysis $\mathrm{SNa}$ on LVM, we assessed whether the predialysis $\mathrm{SNa}$ value was related to the predialysis systolic BP or to the baseline value of LVM, because in previous analyses, we had found that the treatment effect of more frequent dialysis on LVM was strongly associated with baseline LVM, and also there was a trend for a larger reduction in LVM to occur with more frequent dialysis in patients with the highest predialysis systolic BP values at baseline [16]. In the present analysis, the baseline predialysis $\mathrm{SNa}$ level was not related to either the systolic or the diastolic predialysis BP (Table 1)nor to the baseline measure of LVM. Similarly, baseline ejection fractions were similar in the lower and higher predialysis SNa groups.

In thee previous analyses, we found that there appeared to be an interaction between the presence of diabetes and response of LVM to frequent dialysis in the Daily Trial [16], though in the relationship in current data, the modifying effect of diabetes was in the opposite direction. The reduction in LVM with more frequent dialysis was greater in those patients without diabetes. This particular interaction was of borderline significance in all models tested. We did find that the presence of diabetes was increased in the half of patients with lower predialysis SNa values (Table 1), and it is well known that a high predialysis glucose level can lower the measured predialysis $\mathrm{SNa}$ [28-30]. Unfortunately, serum glucose was not in- 


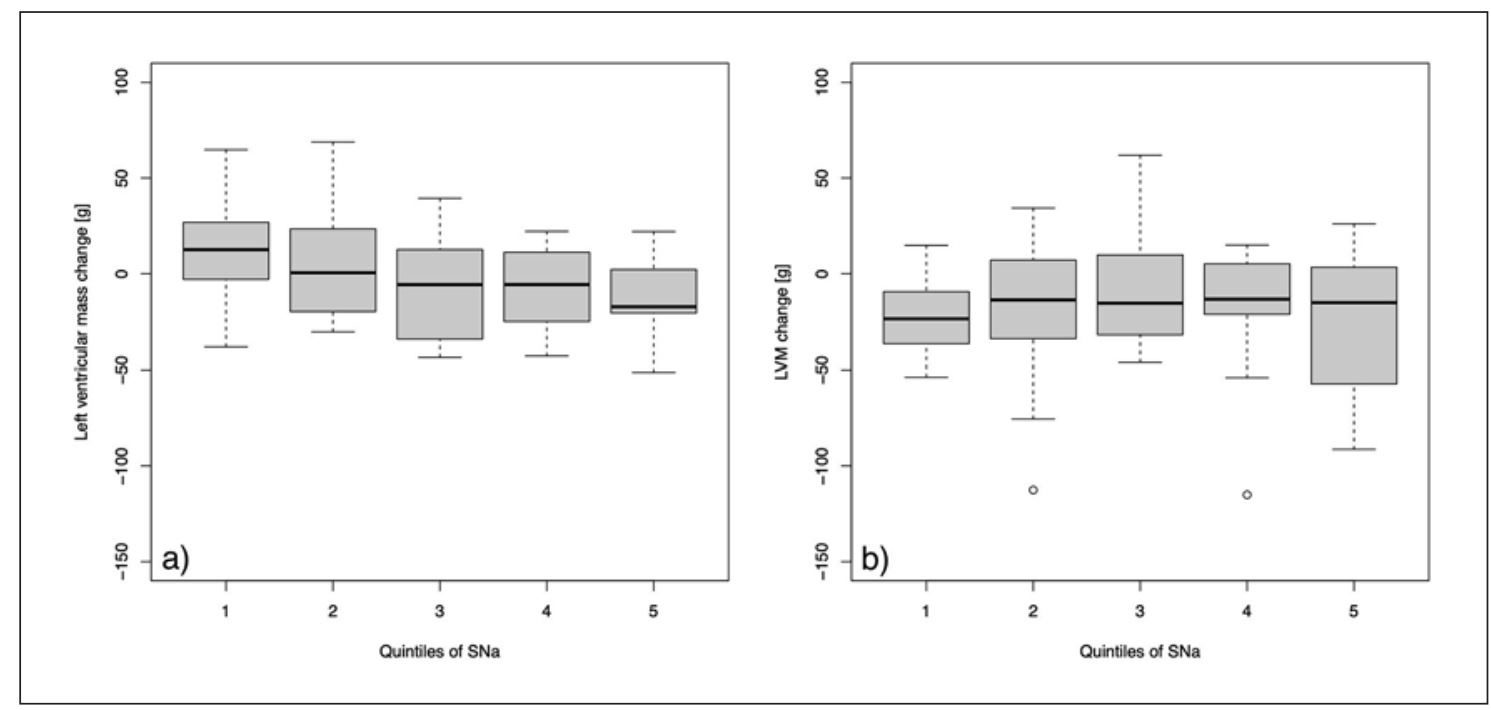

Fig. 3. Changes in LVM from baseline to follow-up after a 12-month study period in the control group (a) and the more frequent HD group (b). Quintiles were defined as follows: Q1: 129-135; Q2: 136-137; Q3: 137-139; Q4: 139-141; and Q5: 141-145 mEq/L. LVM, left-ventricular mass; HD, hemodialysis; SNa, serum sodium.

cluded in the routine measurements in the FHN trial, so it is not possible to calculate whether or not the presence of hyperglycemia alone could account for the lower measured Sna values nor to what extent poorly controlled diabetes, and the associated hyperglycemia, which we were unable to account for, might have been responsible for a lower predialysis SNa. In our current analyses, the modifying effect of predialysis $\mathrm{SNa}$ on the LVM-frequent dialysis interaction was in the opposite direction to the modifying effect of diabetes (Table 1). The modifying effect of low predialysis $\mathrm{SNa}$ on the LVM-frequent dialysis interaction may in fact have been attenuated due to more patients having diabetes in the lower $\mathrm{SNa}$ group than those in the higher $\mathrm{SNa}$ group.

One popular explanation for the beneficial effects of more frequent dialysis on LVH is better control of excess fluid volume, and specifically, ECF volume. In those patients with lower predialysis $\mathrm{SNa}$ values at baseline, the ECF volume did not seem to be increased: left-ventricular end-diastolic volumes were similar in the lower and higher predialysis $\mathrm{SNa}$ groups, and bioimpedance-measured ECF volumes were not significantly different between the groups presenting with lower and higher $\mathrm{SNa}$ (Table 1).

One volume-related measure that was higher in the patients with lower $\mathrm{SNa}$ values was the interdialytic weight gains, whether factored by post-dialysis body weight or by post-dialysis impedance-calculated ECFV (Table 1). In previous publications, we have proposed a new metric to quantify ECF "load" in dialysis patients, which we have termed TIFL [12].

In the present analysis, in addition to dividing patients up based on predialysis $\mathrm{SNa}$ values, we also divided them by the dialysate-GNa. In 62 out of 197 patients so-analyzed, the sodium gradient was $<0$ (DNa less than $\mathrm{SNa}$ ), and in this subset, the mean treatment effect of more frequent dialysis in the Daily Trial was -0.7 (95\% CI -18.2 to 16.8$) \mathrm{g}$, or essentially null, while in 111 out of $197 \mathrm{pa}-$ tients in whom the $\mathrm{DNa}$ was greater than predialysis $\mathrm{SNa}$, the reduction in LVM associated with more frequent $\mathrm{HD}$ was $-25.2(95 \%$ CI -37.6 to -12.7$)$ g. Similarly when we calculated the value for TIFL, when the value for TIFL was $<3 \mathrm{~L} \times$ days, the reduction in LVM was -5.6 (95\% CI -21.5 to 10.4$) \mathrm{g}$, whereas when TIFL was $\geq 3 \mathrm{~L} \times$ days, the reduction was much larger, -26.0 (95\% CI -39.43 to -12.59) g (online supplementary Table 1 and Fig. 2). However, the examination of the interaction between the treatment arm allocation and (a) the baseline predialysis $\mathrm{SNa}$, (b) the sodium gradient, and (c) TIFL as a continuous variable, showed a significant interaction only for the predialysis $\mathrm{SNa}$. This suggests a nonlinear relationship between treatment effect and these potential effect-modifying parameters and requires further investigation and analyses.

Our primary analysis was performed on patients in the FHN Daily Trial. We also divided the patients in the FHN nocturnal trial into 2 groups based on baseline predialysis 
$\mathrm{SNa}$ values, to explore whether or not any trends or differences found in the Daily Trial might be present in the Nocturnal Trial patients. Such trends were present, but none were statistically significant as documented in the online supplementary Tables 2 and 3.

Our post hoc analysis has a number or limitations; among them are a reduced sample size and the lack of available data to explore all possible mechanisms that might potentially explain the modifying effect of baseline predialysis $\mathrm{SNa}$ on the reduction of LVM with more frequent dialysis. We were not able to measure or estimate the nonosmotically stored sodium in storage sites such as skin and muscle over the course of the study. These relatively newly described storages are not yet well enough understood to generate hypotheses as to how frequent HD might have affected them; however, one recently described association between nonosmotically stored sodium and LVM [31] suggests that this topic definitely merits further research. Further, it will be important to validate the model allowing the quantification of TIFL and the pathophysiology correlates in cohorts other than the studiedness. However, in regard of the biological context, the underlying physiology, and the adequate power of our analysis, we believe the found dynamics to be describing a generally applicable phenomenon. Prospective, adequately powered, studies aimed to reduce the $\mathrm{GNa}$ and then to study the effects of the reduction on hard outcomes such as LVM, mortality, and hospitalization; also, soft outcomes such as skin and muscle sodium storage are needed to fully understand the complex interrelationship found in our data.

In summary, of all the potential mechanisms examined, it appears most likely that the association between baseline predialysis $\mathrm{SNa}$ and LVM-response to more frequent dialysis is related to a greater impact on control of ECFV with more frequent dialysis in the slightly hyponatremic patients, in whom the time-averaged sodium-adjusted ECFV load TIFL may be magnified due to a higher sodium gradient. However, the data and mechanistic explanations remain preliminary, and it is not clear to what extent more frequent dialysis should be recommended for slightly hyponatremic patients.

\section{Acknowledgements}

The authors wish to acknowledge and thank the entire FHN Trials Group. Part of the data presented in this manuscript was presented at the Renal Week 2014 of the American Society of Nephrology in Philadelphia, PA, USA and submitted to the Renal Week 2018 of the American Society of Nephrology in San Diego, CA, USA.

\section{Statement of Ethics}

All recruited patients signed informed consent. Both trial protocols were approved by local Institutional Review Boards (Beth Israel Medical Center in New York, NY, USA; Stanford University School of Medicine in Stanford, CA, USA; and Wake Forest School of Medicine, in Winston-Salem, NC, USA) and conducted according to the Declaration of Helsinki. Both protocols were registered (ClinicalTrials.gov number NCT00264758 for the Daily Trial and NCT00271999 for the Nocturnal Trial) and approved and funded by the National Institute of Health (U.S. NIH Grant/Contract number 5U01DK066597).

\section{Conflict of Interest Statement}

Peter Kotanko holds stock in Fresenius Medical Care North America. Nathan W. Levin is a scientific advisor to Aethlon and Affymax, received funding from the US National Institute of Health, and owns stock in Fresenius Medical Care North America. Robert M. Lindsay has unrestricted research support from Fresenius Medical Care Canada. Glenn M. Chertow serves on the Board of Directors of Satellite Healthcare. Jochen Raimann and Peter Kotanko are employees of the Renal Research Institute. All other authors have no relevant conflicts of interest.

\section{Funding Sources}

This study was supported by the National Institutes of Health (NIH), National Institutes of Diabetes and Digestive and Kidney Diseases (NIDDK), the Center for Medicare and Medical Services, and the NIH Research Foundation. Contributors to the NIH Foundation in support of the FHN trials included Amgen, Baxter, and Dialysis Clinics. Additional support was provided by DaVita, Dialysis Clinics, Fresenius Medical Care, Renal Advantage, Renal Research Institute, and Satellite Healthcare.

\section{Author Contributions}

Conceptualization was conceived by J.G.R., C.T.C., J.T.D., T.D., T.G., G.A.K., A.S.K., P.K., B.L., G.B., R.L., M.V.R., G.M.C., and N.W.L.; data curation was performed by T.G., B.L., G.B.; methodology was created by T.G., B.L., G.B., J.G.R., J.T.D., N.W.L., and J.G.R.; formal analysis was performed by T.G., B.L., and G.B.; writing - original draft was performed by J.G.R., C.T.C., J.T.D., G.A., and N.W.L.; writing - review and editing were performed by J.G.R., C.T.C., J.T.D., T.D., T.G., G.A.K., A.S.K., P.K., B.L., G.B., R.L., M.V.R., G.M.C., and N.W.L.

\section{Data Availability Statement}

The data used for this analysis can be requested from the National Institutes of Diabetes and Digestive and Kidney Diseases (NIDDK). 


\section{FHN Trial Group}

Chair, Steering Committee: Kliger A.; NIDDK: Eggers P., Briggs J., Hostetter T., Narva A., Star R.; Centers for Medicare and Medical Services: Augustine B., Mohr P.; Data Coordinating Center - Cleveland Clinic: Beck G. (PI), Fu Z., Gassman J., Greene T., Daugirdas J., Hunsicker L., Larive B., Li M., MacKrell J., Wiggins K., Sherer S., Weiss B.; MRI Core - Ohio State University and Mt. Sinai Medical Center: Rajagopalan S., Sanz J., Dellagrottaglie S., Kariisa M.; Tran T., West J.; Central Quality of Life Core - University of Pittsburgh: Unruh M.; Keene R., Schlarb J.; Central Holter Core - Toronto General Hospital: Chan C.; McGrath-Chong M.; Biospecimen Repository - Fisher BioServices: Frome R., Higgins H., Ke S., Mandaci O., Owens C., Snell C.; Data Safety and Monitoring Board: Eknoyan G. (Chair), Appel L., Cheung A., Derse A., Kramer C., Geller N., Grimm R., Henderson L., Prichard S., Roecker E.

Daily Trial Clinical Sites - University of California San Francisco (UCSF)/Stanford Consortium: Chertow G. (PI); UCSF and San Francisco Bay Area: James S., Chertow G., Tamura M., Hall Y., McCulloch C., Painter P., Gorodetskaya I., Tichy M., Humphreys M., Luan J., Escalada R., Rodriquez R.; UC Davis and Sacramento Area: Depner T., Kaysen G., Suter M., Sonico J., Anderson S.; El Camino Hospital and Satellite Health Care: Ting G., Schiller B., Coplon N., Doss S., Rogers J., Dominguez A., Atwal J., Lemus D.; UCLA and Los Angeles Area: Rastogi A., Nissenson A., Goodman
W., Salusky I., Schweitzer S., Rivas M., Smith M., Gayda P., Hernandez A., Rashid M.; UCSD and San Diego Area: Mehta R., Pepas J., Bharti B., Nabali A., Manaster R., Mathew R., Shah S., Sanz G., Wei J.; University of Texas, San Antonio: Ayus J., Achinger S., Gutierrez M.; Renal Research Institute (RRI) New York Consortium: Levin N. (PI); Bay W., Carter M., Geronemus R., Kuhlmann M., Handelman G., Gotch F., Finkelstein F., Kimmel P., Lacson E., Ornt D., Greenwood R., Vassalotti J., Burrowes J.; RRI New York City: Levin N., Kotanko P., Kaufman A., Winchester J., Meisels I., Radbill B., Chang J., Fofie Y., Ramos R., Sergeyeva O., Callegari J., Arthur B., Tarallo M., Ulloa D., Apruzzese R.; University of Western Ontario: Lindsay R., Suri R., Garg A., Bullas.

Nocturnal Trial Clinical Sites - Wake Forest University School of Medicine Consortium: Rocco M. (PI); Barnes-Jewish/Washington University: Miller B., Riley J., Schuessler R.; Lynchburg Nephrology: Lockridge R., Pipkin M., Peterson C.; Rubin Dialysis: Hoy C., Fensterer A., Steigerwald D.; University of Iowa: Stokes J., Somers D., Hilkin A., Lilli K., Wallace W., Franzwa B., Waterman E.; University of Toronto: Chan C., McGrath-Chong M.; University of British Columbia: Copland M., Levin A., Sioson L., Cabezon E., Kwan S., Roger D.; University of Western Ontario: Lindsay R., Suri R., Champagne J., Bullas R., Garg A., Mazzorato A., Spanner E.; Wake Forest University School of Medicine: Rocco M., Burkart J., Moossavi S., Mauck V., Kaufman T.; Humber River Regional Hospital: Pierratos A., Chan W., Regozo K., Kwok S.

\section{References}

1 Go AS, Chertow GM, Fan D, McCulloch CE, Hsu CY. Chronic kidney disease and the risks of death, cardiovascular events, and hospitalization. N Engl J Med. 2004 Sep 23;351(13): 1296-305

2 Saran R, Li Y, Robinson B, Ayanian J, Balkrishnan R, Bragg-Gresham J, et al. US renal data system 2014 annual data report: epidemiology of kidney disease in the United States. Am J Kidney Dis. 2015;66(1 Suppl 1): Svii.

3 Johansen KL, Young B, Kaysen GA, Chertow GM. Association of body size with outcomes among patients beginning dialysis. Am J Clin Nutr. 2004 Aug;80(2):324-32.

4 Charra B, Chazot C. Volume control, blood pressure and cardiovascular function. Lessons from hemodialysis treatment. Nephron Physiol. 2003;93(4):94-101.

5 Araujo S, Lemes HP, Cunha DA, Queiroz VS, Nascimento DD, Ferreira Filho SR. Cardiac morphology and function in patients with and without residual diuresis on hemodialysis. J Bras Nefrol. 2011 Mar;33(1):74-81.

6 Ozkahya M, Ok E, Cirit M, Aydin S, Akçiçek F, Başçi A, et al. Regression of left ventricular hypertrophy in haemodialysis patients by ultrafiltration and reduced salt intake without antihypertensive drugs. Nephrol Dial Transplant. 1998 Jun;13(6):1489-93.

7 Hur E, Usta M, Toz H, Asci G, Wabel P, Kahvecioglu $S$, et al. Effect of fluid management guided by bioimpedance spectroscopy on car- diovascular parameters in hemodialysis patients: a randomized controlled trial. Am J Kidney Dis. 2013 Jun;61(6):957-65.

8 Ok E, Levin NW, Asci G, Chazot C, Toz H, Ozkahya M. Interplay of volume, blood pressure, organ ischemia, residual renal function, and diet: certainties and uncertainties with dialytic management. Semin Dial. 2017 Sep; 30(5):420-9.

9 Agarwal I, Ide N, Ix JH, Kestenbaum B, Lanske B, Schiller NB, et al. Fibroblast growth factor-23 and cardiac structure and function. J Am Heart Assoc. 2014 Feb 13;3(1):e000584.

10 Tanaka S, Fujita S, Kizawa S, Morita H, Ishizaka N. Association between FGF23, a-klotho, and cardiac abnormalities among patients with various chronic kidney disease stages. PLoS One. 2016;11(7):e0156860.

11 Levin NW, Raimann JG, Rocco MV. Should the knowledge gained from the frequent hemodialysis network (FHN) trials change dialysis practice? Curr Opin Nephrol Hyper tens. 2011 Nov;20(6):577-82.

12 Raimann JG, Chan CT, Daugirdas JT, Depner T, Gotch FA, Greene T, et al. The effect of increased frequency of hemodialysis on volume-related outcomes: a secondary analysis of the frequent hemodialysis network trials. Blood Purif. 2016;41(4):277-86.

13 Raimann JG, Thijssen S, Ramos R, Levin NW More frequent hemodialysis: what do we know? Where do we stand? Contrib Nephrol. 2011;171:10-6
14 Chertow GM, Chertow GM, Levin NW, Beck GJ, Depner TA, Eggers PW, et al. In-center hemodialysis six times per week versus three times per week. N Engl J Med. 2010 Dec 9; 363(24):2287-300.

15 Rocco MV, Lockridge RS Jr., Beck GJ, Eggers PW, Gassman JJ, Greene T, et al. The effects of frequent nocturnal home hemodialysis: the frequent hemodialysis network nocturnal trial. Kidney Int. 2011 Nov; 80(10):1080-91.

16 Chan CT, Greene T, Chertow GM, Kliger AS Stokes JB, Beck GJ, et al. Determinants of left ventricular mass in patients on hemodialysis: frequent hemodialysis network (FHN) trials. Circ Cardiovasc Imaging. 2012 Mar;5(2): 251-61.

17 Daugirdas JT, Chertow GM, Larive B, Pierratos A, Greene T, Ayus JC, et al. Effects of frequent hemodialysis on measures of CKD mineral and bone disorder. J Am Soc Nephrol. 2012 Apr;23(4):727-38.

18 Chan CT, Chertow GM, Daugirdas JT, Greene TH, Kotanko P, Larive B, et al. Effects of daily hemodialysis on heart rate variability: results from the frequent hemodialysis network (FHN) daily trial. Nephrol Dial Transplant. 2014 Jan;29(1):168-78.

19 Chan CT, Greene T, Chertow GM, Kliger AS Stokes JB, Beck GJ, et al. Effects of frequent hemodialysis on ventricular volumes and left ventricular remodeling. Clin J Am Soc Nephrol. 2013 Dec;8(12):2106-16. 
20 Daugirdas JT, Greene T, Rocco MV, Kaysen GA, Depner TA, Levin NW, et al. Effect of frequent hemodialysis on residual kidney function. Kidney Int. 2013 Jan 23;83(5):94958.

21 Unruh ML, Larive B, Chertow GM, Eggers PW, Garg AX, Gassman J, et al. Effects of 6-times-weekly versus 3-times-weekly hemodialysis on depressive symptoms and self-reported mental health: frequent hemodialysis network (FHN) trials. Am J Kidney Dis. 2013 May;61(5):748-58.

22 Suri RS, Garg AX, Chertow GM, Levin NW, Rocco MV, Greene T, et al. Frequent hemodialysis network (FHN) randomized trials: study design. Kidney Int. 2007 Feb;71(4): 349-59.

23 Raimann JG, Abbas SR, Liu L, Zhu F, Larive B, Kotanko P, et al. Agreement of single- and multi-frequency bioimpedance measurements in hemodialysis patients: an ancillary study of the frequent hemodialysis network daily trial. Nephron Clin Pract. 2014 Nov 7; 128(1-2):115-26.
24 Raimann JG, Zhu F, Wang J, Thijssen S, Kuhlmann MK, Kotanko P, et al. Comparison of fluid volume estimates in chronic hemodialysis patients by bioimpedance, direct isotopic, and dilution methods. Kidney Int. 2014 Apr; 85(4):898-908.

25 Kotler DP, Burastero S, Wang J, Pierson RN Jr. Prediction of body cell mass, fat-free mass, and total body water with bioelectrical impedance analysis: effects of race, sex, and disease. Am J Clin Nutr. 1996 Sep;64(3 Suppl):489S97S.

26 Wang Z, St-Onge MP, Lecumberri B, Pi-Sunyer FX, Heshka S, Wang J, et al. Body cell mass: model development and validation at the cellular level of body composition. Am J Physiol Endocrinol Metab. 2004 Jan;286(1): E123-8.
27 R Development Core Team. R: a language and environment for statistical computing. Vienna, Austria: R Foundation for Statistical Computing; 2019.

28 Katz MA. Hyperglycemia-induced hyponatremia - calculation of expected serum sodium depression. N Engl J Med. 1973 Oct 18; 289(16):843-4.

29 Robin AP, Ing TS, Lancaster GA, Soung LS, Sparagana M, Geis WP, et al. Hyperglycemiainduced hyponatremia: a fresh look. Clin Chem. 1979 Mar;25(3):496-7.

30 Penne EL, Raimann JG, Usvyat LA, Thijssen S, Levin NW, Kotanko P. Alignment of the dialysate sodium concentration with the serum sodium: role of plasma water fraction and Donna effects. J Am Soc Nephrol. 2010; 21(Abstract Supplement):434A.

31 Schneider MP, Raff U, Kopp C, Scheppach JB, Toncar S, Wanner C, et al. Skin sodium concentration correlates with left ventricular hypertrophy in CKD. J Am Soc Nephrol. 2017 Jun;28(6):1867-76. 